\title{
Simplified Approach to Glutaric Acidurias: A Mini-Review
}

\author{
Neslihan Yıldırım Saral, Fehime Benli Aksungar*, Mustafa Serteser
}

Acibadem University, School of Medicine, Department of Biochemistry, Acibadem Labmed Clinical Laboratories, Department of Metabolism Istanbul, Turkey

Article Info

\section{Article Notes}

Received: November 27, 2018

Accepted: January 22, 2019

\section{*Correspondence:}

Dr. Fehime Benli Aksungar, Acibadem University, School of Medicine, Department of Biochemistry, Acibadem Labmed Clinical Laboratories, Department of Metabolism Istanbul, Turkey; Email: fehime.aksungar@acibademlabmed.com.tr

(c) 2019 Aksungar FB. This article is distributed under the terms of the Creative Commons Attribution 4.0 International License.
Abstract

Inherited metabolic diseases (IMDs), comprise a large class of genetic diseases affecting the metabolism. Expanded newborn screening from dried dried blood spot (DBS) samples for inborn errors of metabolism has increased the detection of metabolic disorders in asymptomatic newborns and reduced the morbidity and mortality by early interventions. Organic acidurias (OADs) arise from the defects in the intermediary metabolic pathways of carbohydrate, amino acid and fatty acid oxidation, leading to the accumulation of organic acids in tissues and their subsequent excretion in urine. Glutaric acidurias are a group of OADs which have three major types with different genetic mutations affecting different metabolic enzymes. In this mini-review we will compare three types of GA and their genotypes, symptoms, diagnosis, and treatments will be discussed briefly.

Inherited metabolic diseases (IMDs), often referred to as inborn errors of the metabolism (IEM), comprise a large class of genetic diseases affecting the metabolism. The prevalence of these diseases, all together, is estimated to be at least one in every 1,500 individuals in the world ${ }^{1}$. Except for the X-inherited ones there is no difference in the incidences of IMDs between two sexes ${ }^{2}$. Some metabolic disorders can be diagnosed through routine newborn metabolic screening tests at birth while others are identified only after the patient develops symptoms of a metabolic disorder. Newborn screenings for metabolic disorders (NBS) are conducted in many of the developed and developing countries worldwide. The main goal of newborn screening for IEM is to reduce morbidity and mortality through early interventions such as dietary and pharmacological treatments. In recent years, expanded NBS used in tandem mass spectrometry has increased the detection of many IEMs in asymptomatic newborns. The definite diagnosis of such patients is achieved through genetic analysis. Treatment for IMDs depends on the type and severity of the disease, and since there are so many types of IMDs, treatments may vary from dietary restrictions and supplements to liver transplants ${ }^{1}$.

Organic acidurias (OADs) are an important class of IMDs arising from the defects in the intermediary metabolic pathways of carbohydrate, amino acid and fatty acid oxidation, leading to the accumulation of organic acids in tissues and their subsequent excretion in urine ${ }^{2}$. More than 100 different organic acids are excreted in urine under these conditions ${ }^{2}$. The major organic aciduria disorders include propionic aciduria (PA), methyl malonic aciduria (MMA), branched chain organic aciduria, glutaric acidurias (GAs) and multiple carboxylase deficiencies ${ }^{2,3}$. Organic acidurias usually present with hyperammonemia with a high anion gap metabolic acidosis, in addition to hypoglycemia and ketonuria. The 
major clinical features include developmental and mental retardation, cardiac dysfunction, lethargy, coma, seizures, hypotonia, failure to thrive, hepatomegaly, and respiratory distress ${ }^{2}$.

Glutaric acidurias are a group of OADs which have three major types with different genetic mutations affecting different metabolic enzymes and all three having an autosomal recessive inheritance. In this mini-review we will compare three types of GA and their symptoms, diagnosis, and treatments will be discussed briefly in the light of literature.

\section{Glutaric Aciduria Type I (GA-I, OMIM 231670 , GARD 6522, ORPHA 25):}

Glutaric aciduria type I (GA-I) is an autosomal recessive organic aciduria caused by glutaryl-CoA dehydrogenase (GCDH) deficiency with an estimated overall prevalence of 1 in 100,000 newborns. GA-I is considered to be a neurological disorder and a cerebral organic aciduria 4 . Since the initial description of two index patients in 1975 and 2011 , only 500 cases have been reported worldwide ${ }^{5,6}$. The GCDH gene which plays a key role in this disorder is localized on chromosome 19p13.2, and a deficiency in this particular gene results in an impaired metabolism of L-lysine, L-hydroxylysine and L-tryptophan, leading to the accumulation of 3-hydroxyglutaric acid (3-OH-GA), glutaconic acid, and glutarylcarnitine $(\mathrm{C} 5 \mathrm{DC})^{7}$ (Table 1). Increased urinary concentrations of $3-0 \mathrm{H}-\mathrm{GA}$ is the most sensitive biochemical marker for diagnosis and the diagnostically relevant metabolite is elevated C5DC in dried blood spot (DBS) screening. However since NBS in newborns reflects the metabolic state of the mother and the infant, NBS laboratories should be aware that elevated C5DC concentrations may indicate maternal GA$\mathrm{I}^{8,9}$. In addition, some laboratories are also using ratios of C5DC to other measured acylcarnitines such as C5DC/ C8 or C5DC/C16 in GA-I diagnosis ${ }^{10,11}$ (Table 1). Aside from the primary disease maternal GA-I cases can be diagnosed based on the findings in their offspring. Women with GA-I can be diagnosed retrospectively following a positive newborn screening test in their babies due to the elevated metabolites that can easily cross the placenta from maternal blood ${ }^{12}$. Babies are mainly asymptomatic or show only transient mild neurologic symptoms and although not treated they are not expected to develop metabolic complications during pregnancy, delivery or the puerperium $^{13,14}$.

For further diagnosis, glutaryl-CoA dehydrogenase

Table 1. Genotypes, Phenotypes, Laboratory Findings and Possible Treatments of Glutaric Acidurias

\begin{tabular}{|c|c|c|c|c|c|c|c|c|}
\hline GA Type & Prevalance & Gene & Inheritance & DBS Results & $\begin{array}{c}\text { Urine Organic Acid } \\
\text { Results }\end{array}$ & $\begin{array}{l}\text { Clinical } \\
\text { Symptoms }\end{array}$ & Treatment & References \\
\hline $\begin{array}{c}\text { GA } \\
\text { Type1 }\end{array}$ & 1:100000 & $\mathrm{GCDH}$ & AR & $\begin{array}{l}\text { Elevated } \\
\text { C5DC } \\
\text { C5DC /C16 } \\
\text { Ratio } \\
\text { C5DC/C8 } \\
\text { Ratio }\end{array}$ & $\begin{array}{c}\text { Elevated Glutaric } \\
\text { acid (GA), } \\
\text { 3-hydroxyglutaric } \\
\text { acid (3-OH-GA), } \\
\text { Glutaconic acid } \\
\text { (less frequently) }\end{array}$ & $\begin{array}{l}\text { Macrocephaly } \\
\text { Dystonia, } \\
\text { Seizures } \\
\text { Delayed motor } \\
\text { skills, } \\
\text { Metabolic } \\
\text { acidosis }\end{array}$ & $\begin{array}{c}\text { low lysine } \\
\text { and increased } \\
\text { glucose intake } \\
\text { diet } \\
\text { L-Carnitine } \\
\text { Riboflavin } \\
\text { Baclofen and } \\
\text { Benzodiazepines }\end{array}$ & $6,11,15,34$ \\
\hline $\begin{array}{c}\text { GA } \\
\text { Type2 }\end{array}$ & 1:200000 & $\begin{array}{l}\text { ETFA } \\
\text { ETFB } \\
\text { ETFDH }\end{array}$ & AR & $\begin{array}{l}\text { Elevated } \\
\text { Short/ } \\
\text { medium/ } \\
\text { long chain } \\
\text { acylcarnitines } \\
\text { From C4 to } \\
\text { C18 }\end{array}$ & $\begin{array}{c}\text { Elevated Glutaric } \\
\text { acid, } \\
\text { Lactic acid, } \\
\text { Ethylmalonic acid, } \\
\text { Butyric and } \\
\text { Isobutyric acid, } \\
\text { 2-methyl-butyric } \\
\text { acid, } \\
\text { Isovaleric acid, } \\
\text { Suberic acid, } \\
\text { Sebacic acid and } \\
\text { Adipic acid }\end{array}$ & $\begin{array}{c}\text { Respiratory } \\
\text { failure, } \\
\text { Cardiomyopathy, } \\
\text { Hypotonia, } \\
\text { Metabolic } \\
\text { acidosis, } \\
\text { Hypoglycemia, } \\
\text { Congenital } \\
\text { anomalies, } \\
\text { Lethargy }\end{array}$ & $\begin{array}{l}\text { Low-fat diet, } \\
\text { Avoidance } \\
\text { of fasting, } \\
\text { Riboflavin, } \\
\text { L-carnitine and } \\
\text { glycine, } \\
\text { Sodium-D,L-3 } \\
\text { hydroxybutyrate } \\
\text { (NaOHB) }\end{array}$ & $18,21,22,26,34$ \\
\hline $\begin{array}{c}\text { GA } \\
\text { Type3 }\end{array}$ & unknown & SUGCT & AR & $\begin{array}{c}\text { Not } \\
\text { detectable by } \\
\text { bloodspot } \\
\text { acylcarnitine- } \\
\text { based } \\
\text { newborn } \\
\text { screening }\end{array}$ & $\begin{array}{c}\text { Persistent isolated } \\
\text { elevation of glutaric } \\
\text { acid (GA) }\end{array}$ & $\begin{array}{l}\text { Not spesific } \\
\text { Mostly } \\
\text { asymptomatic }\end{array}$ & $\begin{array}{c}\text { No Therapy/ } \\
\text { Symptomatic } \\
\text { Therapy }\end{array}$ & $27,28,30,31,34$ \\
\hline
\end{tabular}

stearoylcarnitine; GCDH: Glutaryl-CoA dehydrogenase; ETF: electron transfer flavoprotein; ETFDH: electron transfer flavoprotein dehydrogenase; SUGCT: succinyl-CoA:glutarate-CoA transferase; AR: Autosomal recessive 
activity in cultured fibroblasts can be measured and mutation analysis carried out on genomic DNA ${ }^{15}$. To date, two biochemically defined subgroups of GA-I patients have been described based on the urinary metabolite excretion of GA, i.e., low and high excretors ${ }^{16}$. Low excreting patients have the same risk of developing striatal injury as the high excretors and should not be considered to have a "mild" clinical phenotype ${ }^{17}$.

The initial progression of clinical symptoms in cases of GA-I is slow; hence GA-I is frequently left undiagnosed until an acute metabolic crisis occurs. A child suffering from GA-I usually presents with macrocephaly which is found in $75 \%$ of GA-I patients during infancy ${ }^{18,19}$. Neuroradiologic findings in GA-I may occur in some cases even before the onset of neurologic symptoms. The most striking finding at brain imaging in GA-I is the presence of very wide cerebrospinal fluid (CSF) spaces anterior to the temporal lobes and within the sylvian fissures These findings although not present in all cases might help the doctors recognize the disease in an asymptomatic child, evaluated for macrocephaly, before irreversible brain damage has developed ${ }^{20}$.

Clinical presentations with acute encephalopathic crises are seen mostly between 6 and 18 months and induced by febrile illness, fasting, or immunization. Dystonia and extrapyramidal symptoms such as athetosis, seizures, and intellectual disability may be the other signs in GA-I. However some patients with GA-I remain asymptomatic, even in the adulthood ${ }^{21}$. Glutaric aciduria type I suspicion may be based on typical risk factors such as family history, consanguineous marriage, and deceased sibling. Further laboratory findings may include severe acidosis, ketosis, hyperammonemia, and abnormal liver function tests. The early diagnosis of GA-I is essential, since the metabolic symptoms can be usually prevented by carnitine supplementation and a diet that is low in lysine and tryptophan to reduce glutaric acid production, and also may include supplementation with L-carnitine, riboflavin ${ }^{15}$. GA-I is a good candidate for NBS, and the aim of NBS in GA-I cases is to reduce the risk of irreversible neurological disease following the striatal injury ${ }^{4}$.

\section{Glutaric Acidemia Type II (GA-II, OMIM 231680,} ARD 6523, ORPHA 26791)

Glutaric aciduria type II (GA-II) also known as multiple acyl-CoA dehydrogenase deficiency (MADD) is an autosomal recessive disease caused by a defect in electron transfer flavoprotein (ETF) or ETF dehydrogenase (ETFDH), resulting in deficiencies in multiple acyl-CoA dehydrogenases, such as short-, medium-, and long-chain acyl CoA dehydrogenases ${ }^{22}$. GA-II is mainly caused by homozygous or compound heterozygous mutations in the ETFA, ETFB or ETFDH genes. Mutations in ETFA and ETFB are usually associated with the neonatal forms, whereas
ETFDH mutations often present as late-onset forms ${ }^{23}$. There are three main clinical phenotypes of GA-II: First, the neonatal form with congenital anomalies, second, the neonatal form without congenital anomalies; and third, the late onset form with myopathic phenotype, and rarely, metabolic acidosis ${ }^{24}$. Muscle weakness is a common finding in late-onset presentations of GA-II. Although muscle biopsy is usually invaluable in the diagnosis of myopathies, histological findings of lipid deposition can be an initial clue for the diagnosis of GA-II in patients with myopathy ${ }^{22,25}$.

The clinical presentation and disease onset may vary depending on the location and nature of the mutations ${ }^{26}$. Many patients with GA-II present with hypotonia, tachypnea, hypoglycemia, and, often, neonatal death, or with a Reye's syndrome-like illness.

Acylcarnitine analysis in tandem mass spectrometry is a preferred diagnostic tool for GA-II cases. Acylcarnitine profiling by tandem mass spectrometry, screening of serum or dried blood spot samples characteristically shows increased concentrations of short-, medium-, and long-chain acylcarnitines ${ }^{26}$. A urinary organic acid analysis by GC/MS shows an increased excretion of characteristic compounds such as adipate, suberate, sebacate, glutarate, 2-hydroxyglutarate, ethylmalonate or isovalerylglycine, as the corresponding metabolites derived from defective steps $^{27}$. In late-onset cases, the elevation of acylcarnitine levels may be mild and atypical, or detectable only during an acute episode. Under these circumstances, genetic screening is the key to establish a definitive diagnosis ${ }^{23}$. Furthermore, novel compound heterozygous mutations in ETF have been described in many individual cases in the literature $\mathrm{e}^{23,28}$.

The conventional treatment of GA-II, including a protein- and fat-restricted, carbohydrate-rich diet, and riboflavin, glycine, and L-carnitine supplementation, may be effective in mildly affected patients, however, in some cases results can be disappointing. Riboflavin is the precursor of flavin adenine dinucleotide (FAD) and flavin mononucleotide (FMN), and is considered to be the main therapeutic agent, due to its favorable effect on flavin-dependent mitochondrial enzymes and result in a dramatic improvement in the muscular strength, tone and trophism as well as in the aerobic performance ${ }^{29}$. A racemic mixture of sodium D,L-3-hydroxybutyrate (NaHB) is a promising treatment option aiming to replace the deficient endogenous ketone body production which is needed not only for energy supply, but also for the synthesis of complex cell and tissue components such as myelin in the central nervous system ${ }^{30}$. Cardiomyopathy is a frequent cause of death in MADD which warrants experimental treatment. $\mathrm{D}, \mathrm{L}-3$-hydroxybutyrate is an additional therapeutic option for cardiomyopathy and cerebral dysfunction in severe fatty acid oxidation defects. Treatment with D,L-3- 
hydroxybutyrate is safe and effective and not associated with any notable adverse side-effects ${ }^{28,31}$.

\section{Glutaric Aciduria Type III (GA-III, OMIIM 231690; GARD 12469; ORPHA 35706)}

Glutaric aciduria type III (GA-III) is often considered a "non-disease" that is caused by mutations in the succinylCoA:glutarate-CoA transferase (SUGCT) gene, that produces deficiency of succinate-hydroxymethylglutarate CoA-transferase, and provoking the decreased conversion of free glutaric acid to glutaryl-CoA with no symptoms. It remains less well known, characterized or understood than other types of $\mathrm{GA}^{32,33}$. The succinyl-CoA:glutarateCoA transferase gene that plays a role in this disorder is localized on chromosome $7 \mathrm{p} 14.1^{34}$. GA-III is also an autosomal recessive disorder like the other GAs. GlutarylCoA oxidase deficiency is a peroxisomal disorder leading to glutaric aciduria and the prevalence is unknown ${ }^{34}$. With no known biomarker other than notable glutaric aciduria without elevation of any other markers of GA-I or GA-II, and an increased glutaric acid excretion following lysine loading, GA-III is thought to be a "diagnosis of exclusion," following suspicion based on clinical manifestations or metabolite profiles ${ }^{32}$.

Bennett et al. first described the case of GA-III, a one year-old girl with failure to thrive, beta-thalassemia, abnormal urinary amounts of glutaric acid and a lack of detectable activity of peroxisomal glutaryl-CoA oxidase ${ }^{35}$. Later on, Knerr et al. reported three cases with no distinctive phenotype, and Sherman et al. also reported three healthy children who excreted large quantities of glutarate but low 3-hydroxyglutarate, consistent with the phenotype of GAIII based on the screening of Amish infants, who received no treatment and remained healthy for more than 15 years $^{36,37}$.

\section{References}

1. Raghuveer TS, Garg U, Graf WD. Inborn errors of metabolism in infancy and early childhood: an update. Am Fam Physician. 2006; 73(11): 1981-90.

2. Vaidyanathan K, Narayanan MP, Vasudevan DM. Organic Acidurias: An Updated Review. Indian J Clin Biochem. 2011; 26(4): 319-325.

3. Villani GR, Gallo G, Scolamiero E, et al. "Classical organic acidurias": diagnosis and pathogenesis. Clin Exp Med. 2017; 17(3): 305-323.

4. Boy N, Muhlhausen C, Maier EM, et al. Proposed recommendations for diagnosing and managing individuals with glutaric aciduria type I: second revision. J Inherit Metab Dis. 2017; 40(1): 75-101.

5. Goodman SI, Markey SP, Moe PG, et al. Glutaric aciduria; a "new" disorder of amino acid metabolism. Biochem Med. 1975; 12(1): 12-21.

6. Kolker S, Christensen E, Leonard JV, et al. Diagnosis and management of glutaric aciduria type I-revised recommendations. J Inherit Metab Dis. $2011 ; 34(3)$ : 677-94.

7. Tsai FC, Lee HJ, Wang AG, et al. Experiences during newborn screening for glutaric aciduria type 1: Diagnosis, treatment, genotype, phenotype, and outcomes. J Chin Med Assoc. 2017; 80(4): 253-261.
8. Al-Dirbashi OY, Jacob M, Al-Amoudi M, et al. Quantification of glutaric and 3hydroxyglutaric acids in urine of glutaric acidemia type I patients by HPLC with intramolecular excimer-forming fluorescence derivatization. Clin Chim Acta. 2005; 359(1-2): 179-188.

9. Crombez EA, Cederbaum SD, Spector E, et al. Maternal glutaric acidemia type I identified by newborn screening. Mol Genet Metab. 2008; 94(1): 132-134.

10. Lindner M, Ho S, Fang-Hoffmann J, et al. Neonatal screening for glutaric aciduria type I: strategies to proceed. J Inherit Metab Dis. 2006; 29(2-3): 378-382.

11. Kaya Ozcora GD, Gokay S, Canpolat M, et al. Glutaric Acidemia Type 1: A Case of Infantile Stroke. JIMD Rep. 2018; 38: 7-12.

12. Crombez EA, Cederbaum SA, Spector E, et al.Maternal Glutaric Acidemia, Type I Identified by Newborn Screening. Mol Genet Metab. 2008; 94(1): 132-134.

13. Garcia p, Martins E, Diogo L, et al. Outcome of three cases of untreated maternal glutaric aciduria type I. Eur J Pediatr. 2008; 167: 569-573.

14. Kolker S. Glutaric aciduria type I. Inherited metabolic disease in adults, Oxford monographs of medical genetics. HollakC, Lachmann R (eds). 2016; Oxford University Press, Oxford.

15. Gordon N. Glutaric aciduria types I and II. Brain Dev. 2006; 28(3): 136-40.

16. Baric I, Wagner L, Feyh P, et al. Sensitivity of free and total glutaric and 3-hydroxyglutaric acid measurement by stable isotope dilution assays for the diagnosis of glutaric aciduria type I. J Inherit Metab Dis. 1999; 22(8): 867-882.

17. Christensen E, Ribes A, Merinero B, et al.Correlation of genotype and phenotype in glutaryl-CoA dehydrogenase deficiency. J Inherit Metab Dis. 2004; 27(6): 861-868.

18. Babu RP, Bishnupriya G, Thushara PK, et al. Detection of glutaric acidemia type 1 in infants through tandem mass spectrometry. Mol Genet Metab Rep. 2015; 3: 75-9.

19. Bjugstad KB, Goodman SI, Freed CR. Age at symptom onset predicts severity of motor impairment and clinical onset outcome of glutaric aciduria type I. J Pediatr. 2000; 137(5): 681-686.

20. Brismar J, Ozand PT. CT and MR of the brain in glutaric acidemia type I: Areview of 59 published cases and a report of 5 new patients. Am J Neuroradiol. 1995; 16: 675-683.

21. Kolker S, Garbade S, Greenberg CR, et al. Natural history, outcome, and treatment efficacy in children and adults with glutaryl-CoA dehydrogenase deficiency. Pediatr Res. 2006; 59(6): 840-847.

22. 22.Yamada $K$, Kobayashi $H$, Bo $R$, et al. Clinical, biochemical and molecular investigation of adult-onset glutaric acidemia type II: Characteristics in comparison with pediatric cases. Brain Dev. 2016; 38(3): 293-301.

23. Xue Y, Zhou Y, Zhang K, et al. Compound heterozygous mutations in electron transfer flavoprotein dehydrogenase identified in a young Chinese woman with late-onset glutaric aciduria type II. Lipids Health Dis. 2017; 16(1): 185.

24. Ersoy EO, Rama D, Unal 0, et al. Glutaric aciduria type 2 presenting with acute respiratory failure in an adult. Resp Med Case Rep. 2015; 15: 92-4.

25. Beresford MW, Pourfarzam M, Turnbull DM, et al. So doctor, what exactly is wrong with my muscles? Glutaric aciduria type II presenting in a teenager. Neuromuscular Disorders. 2006; 16: 269-273.

26. Isıkay S, Yaman A, Ceylaner S. An infant with glutaric aciduria type IIc diagnosed with a novel mutation. Turk J Pediatr. 2017; 59(3): 315317. 
27. Yamaguchi S, Orii T, Suzuki Y, et al. Newly identified forms of electron transfer flavoprotein deficiency in two patients with glutaric aciduria type II. Pediatr Res. 1991; 29(1): 60-3.

28. Saral NY, Aksungar FB, Coskun J, et al. Glutaric acidemia type II patient with thalassemia minor and novel ETF-A gene mutations. World J Clin Cases. 2018; 6(14)- In Press.

29. Rosa M, Pascarella A, Parenti G, et al. Developmental evolution in a patient with multiple acyl-coenzymeA dehydrogenase deficiency under pharmacological treatment. Eur J Paediatr Neurol. 2012; 16(2): 203-5.

30. Gautschi M, Weisstanner C, Slotboom J, et al. Highly efficient ketone body treatment in multiple acyl-CoA dehydrogenase deficiencyrelated leukodystrophy. Pediatr Res. 2015; 77(1-1): 91-8.

31. Van Hove JL, Grunewald S, Jaeken J, et al. D,L-3-hydroxybutyrate treatment of multiple acyl-CoA dehydrogenase deficiency (MADD) Lancet. 2003; 361(9367): 1433-5.
32. Waters PJ, Kitzler TM, Feigenbaum A, et al. Glutaric Aciduria Type 3: Three Unrelated Canadian Cases, with Different Routes of Ascertainment. JIMD Rep. 2018; 39: 89-96.

33. La Serna-Infantes J, Pastor MC, Trubnykova M, et al. Novel contiguous gene deletion in peruvian girl with Trichothiodystrophy type 4 and glutaric aciduria type 3. Eur J Med Genet. 2018; 61(7): 388-392.

34. ORPHANET: https://www.orpha.net

35. Bennett MJ, Pollitt RJ, Goodman SI, et al. Atypical riboflavin-responsive glutaric aciduria, and deficient peroxisomal glutaryl-CoA oxidase activity: a new peroxisomal disorder. J Inherit Metab Dis. 1991; 14(2): 165-73.

36. Knerr I, Zschocke J, Trautmann U, et al. Glutaric aciduria type III: a distinctive non-disease? J Inherit Metab Dis. 2002; 25(6): 483-90.

37. Sherman EA, Strauss KA, Tortorelli S, et al. Genetic mapping of glutaric aciduria, type 3 , to chromosome 7 and identification of mutations in c7orf10. Am J Hum Genet. 2008; 83(5): 604-9. 